\title{
Genome profiling of ovarian adenocarcinomas using pangenomic BACs microarray comparative genomic hybridization Donatella Caserta*1, Moncef Benkhalifa ${ }^{2}$, Marina Baldi3 ${ }^{3}$, Francesco Fiorentino $^{3}$, Mazin Qumsiyeh ${ }^{2,4}$ and Massimo Moscarini ${ }^{1}$
} \author{
Laboratory, SiParadigm Laboratories, 690 Kinderkamack Rd, Oradell, NJ, USA \\ Email: Donatella Caserta* - donatellacaserta@virgilio.it; Moncef Benkhalifa - atl78@aol.com; \\ Marina Baldi - marinabaldi@consultoriogenetica.it; Francesco Fiorentino - fiorentino@laboratoriogenoma.it; \\ Mazin Qumsiyeh - qumsi001@ hotmail.com; Massimo Moscarini - massimo.moscarini@viriglio.it \\ * Corresponding author
}

Address: ${ }^{1}$ Oby/Gyn Dept. Saint Andrea Hospital, University of Roma La Sapienza, Rome, italy, ${ }^{2}$ Genetics \& IVF, A TL R\&D Laboratory, La Verrière france \& UNILABS Laboratories, Geneva, Switzerland, ${ }^{3}$ Molecular Biology \& Cytogenetics, Genoma Laboratories, Rome, italy and ${ }^{4}$ Cytogenetics

Published: 20 May 2008

Molecular Cytogenetics 2008, I:10 doi:10.1186/1755-8166-1-10
Received: 3 January 2008

Accepted: 20 May 2008

This article is available from: http://www.molecularcytogenetics.org/content/l/I/I0

(c) 2008 Caserta et al; licensee BioMed Central Ltd.

This is an Open Access article distributed under the terms of the Creative Commons Attribution License (http://creativecommons.org/licenses/by/2.0), which permits unrestricted use, distribution, and reproduction in any medium, provided the original work is properly cited.

\begin{abstract}
Background: Routine cytogenetic investigations for ovarian cancers are limited by culture failure and poor growth of cancer cells compared to normal cells. Fluorescence in situ Hybridization (FISH) application or classical comparative genome hybridization techniques are also have their own limitations in detecting genome imbalance especially for small changes that are not known ahead of time and for which FISH probes could not be thus designed.
\end{abstract}

Methods: We applied microarray comparative genomic hybridization (A-CGH) using one mega base BAC arrays to investigate chromosomal disorders in ovarian adenocarcinoma in patients with familial history.

Results: Our data on 10 cases of ovarian cancer revealed losses of 6q (4 cases mainly mosaic loss), $9 \mathrm{p}$ ( 4 cases), 10q ( 3 cases), $21 \mathrm{q}$ ( 3 cases), 22q (4 cases) with association to a monosomy $X$ and gains of $8 q$ and $9 q$ (occurring together in 8 cases) and gain of $12 p$. There were other abnormalities such as loss of $17 p$ that were noted in two profiles of the studied cases. Total or mosaic segmental gain of $2 p, 3 q, 4 q, 7 q$ and $13 q$ were also observed. Seven of 10 patients were investigated by FISH to control array CGH results. The FISH data showed a concordance between the 2 methods.

Conclusion: The data suggest that A-CGH detects unique and common abnormalities with certain exceptions such as tetraploidy and balanced translocation, which may lead to understanding progression of genetic changes as well as aid in early diagnosis and have an impact on therapy and prognosis.

\section{Background}

A number of strategies have been used for early detection of ovarian cancer and follow-up. CA-125 tumor marker investigation and trans vaginal ultrasound are the most common used procedures [1,2]. An increase of CA-125 marker has been shown to predate clinical or scan evidence of relapse in approximately $70 \%$ of patient with ovarian cancer [3]. For Genome disorders investigation 
classical cytogenetic, fluorescence in situ hybridization and comparative genome hybridization methods were applied in cancers [4-6]. Recent studies suggest that genomic changes can be useful for cancer grading [7]. For example, a study by Simon et al. [8] showed that breakpoints in regions $1 \mathrm{p} 3$ and $11 \mathrm{p} 1$ are important early events and distinguish a class of tumors associated with poor prognosis in ovarian adenocarcinoma. Genomic changes in ovarian cancers were investigated by using various techniques, each with its own limitations. For example fluorescence in situ hybridization was used by Liehr et al. [9], on 25 cases of ovarian carcinomas using alphoid probes noting loss of chromosomes 17 and 20 and gain of chromosomes 7, 1, 8 and 11 [10]. Classical comparative genomic hybridization was also used but is limited in their resolution [11-14]. Gene expression and proteomics arrays were applied to assess gene expression changes which could be due to both genotype changes, regulation pathway changes, or epigenetic [15-19]. Single nucleotide polymorphism arrays were also used recently to detect some micro deletions and amplifications in serous ovarian carcinomas $[20,21]$.

Array comparative genome hybridization (A-CGH) using spotted bacterial artificial chromosomes (BACs), phage artificial chromosomes (PACs), cDNAs or oligonucleotides provides distinct advantages in specificity, sensitivity and high resolution genome analysis [22-28]. Microarray CGH combined to immunohistochemical analysis was applied for genes amplification and prognostic markers analysis in ovarian cancer [29]

Micro arrays provide distinct advantages over conventional and molecular cytogenetics (pre and post natal, cancer and oncology) analysis because they have the potential to detect the majority of microscopic and sub microscopic chromosomes changes from any DNA sources with or without whole genome amplification $[30,31]$. Other advantage of A-CGH is the increase in res- olution that can be achieved compared to chromosomebased CGH. The only limitations of CGH (both conventional and A-CGH) is the inability to detect polyploidy or balanced chromosome abnormalities. But polyploidy can be easily detected by FISH, micro satellite analysis or flow cytométrie and balanced translocations will still be detectable using classic cytogenetics or FISH.

\section{Results}

The main endocrinological observation in these patients was an excess of sex steroids production. Histological findings revealed 9 of 10 patients with serous papillary cystadenocarcinoma (eight grade III and one grade II), the remaining patient showed endometrial carcinoma with papillary aspects and squamous metaplasia (Table 1). The data we obtained from A-CGH showed that all ten patients have an abnormal genome profile with both unique and common changes (Table 2 and Figures 1, 2, 3 ). The most common findings were loss of $6 \mathrm{q}$ (4 cases with mosaic loss of $6 q), 9 p$ ( 4 cases), 10q (3 cases), 21q ( 3 cases), 22q ( 4 cases) and gain of $8 \mathrm{q}$ and $9 q$ (occurring together in 8 cases) and gain of 12p. Two cases with monosomy $\mathrm{X}$ were observed. A micro deletion of $17 \mathrm{p}$ terminal was observed in 2 cases. Some cases showed also a genomic profile with total or mosaic segmental gain on chromosomes 2p, 3q,4q, 7q and 13q. Seven of 10 patients $(1,2,4,5,6,7$, and 9) were analyzed by FISH for aneuploidy confirmation using a cocktail of bacs probes for each specific abnormal chromosome region. We were not able to analyze the remaining 3 patients because of the limited material. The obtained data by FISH was in concordance with the CGH array except the patient number 1 and 9. For the 2 patients we couldn't confirm the mosaic loss of $18 \mathrm{q}$ for patient 1 and the segmental loss of $12 \mathrm{q} 22-12 \mathrm{q} 23$ for patient 9 (see Fig 4).

\section{Discussion}

While early detection predicts treatment success, fewer than $25 \%$ of ovarian cancers are currently detected at stage

Table I: Hystological Findings

\begin{tabular}{|c|c|c|c|c|}
\hline $\mathbf{N}^{\circ}$ case & Name (initials) & Age & Grading & Hystological Diagnosis \\
\hline 1 & PG & 44 & pT3c pNO pMX; Stage III C grade G2 (AICC 2002) & cystoadenocarcinoma \\
\hline 2 & TS & 37 & PTla pNO pMx Stage IA (AICC2002) & $\begin{array}{l}\text { Endometrial carcinoma of the right ovary with papillary aspects and } \\
\text { squamous metaplasia }\end{array}$ \\
\hline 3 & VM & 65 & PTI b pNO G3 Stage IB (AICC 2002) & Cystoadenocarcinoma serous Papillary left and right ovary G 3 \\
\hline 4 & LR & 84 & $\begin{array}{l}\text { PT2a pNX pMX Stage } 2 A \text { G } 3 \text { (AICC 2002) Stage IIA } \\
\text { FIGO) }\end{array}$ & Cystoadenocarcinoma, serous papillary left and right ovary G3 \\
\hline 5 & AW & 75 & Stage IV G3 & Cystoadenocarcinoma, serous papillary G3 \\
\hline 6 & FR & 73 & pT2a pNI pMX Stage IIIC (AICC 2002) & Cystoadenocarcinoma serous papillary left ovary G3 \\
\hline 7 & $\mathrm{PL}$ & 50 & $\begin{array}{l}\text { PT2a pNX pMX Stage 2A G3 (AICC 2002) Stage IIA } \\
\text { FIGO) }\end{array}$ & Cystoadenocarcinoma serous papillary left and right ovary G3 \\
\hline 8 & MA & 64 & $\begin{array}{l}\text { PT2a pNX pMX Stage 2A G3 (AICC 2002) Stage IIA } \\
\text { FIGO }\end{array}$ & Cystoadenocarcinoma serous papillary left and right ovary G3 \\
\hline 9 & MF & 68 & PT3c pNI pMX Stage mc G3 (AICC 2002) & Cystoadenocarcinoma serous papillary left ovary \\
\hline 10 & WDT & 45 & PT3c pNI pMX Stage IIIC G3 (AICC 2002) & Cystoadenocarcinoma serous papillary left and right ovary G3 \\
\hline
\end{tabular}


Table 2: Genome profile results of the 10 patients

\begin{tabular}{|c|c|c|c|c|}
\hline $\mathbf{N}^{\circ}$ & Name & Segmental gain & Segmental loss & Other abnormalities \\
\hline I & PG & Segmental gain on $2 p, 7 q$, and $13 q$ arms & $\begin{array}{l}\text { Mosaic segmental loss on } 10 \mathrm{q} \text { and } 18 \mathrm{q} \\
\text { arms }\end{array}$ & \\
\hline 2 & TS & Segmental gain on $8 q, 9 q, 12 p$, and $13 q$ arms & Total loss of $9 p$ and $10 q$ arms & Monosomy 21 and 22 \\
\hline 3 & VM & $\begin{array}{l}\text { Mosaic segmental gain on } 3 q \text { and } 4 q \text { arms Total gain of } 7 q, 8 q \text {, } \\
9 q, 13 q \text { arms }\end{array}$ & Mosaic segmental loss on $6 q$ arms & Monosomy 22 \\
\hline 4 & LR & $\begin{array}{l}\text { Mosaic segmental gain on } 3 q \text { and } 4 q \text { Total gain of } 2 p, 7 q, 8 q \text {, } \\
9 q 13 q \text { and } 17 q \text { arms }\end{array}$ & Mosaic segmental loss on $6 q$ arms & Monosomy 21 \\
\hline 5 & AW & Segmental gain on $12 \mathrm{p}$ arms & Total loss of chromosome 10 & $\begin{array}{l}\text { Segmental disorder of chromosome } 13 \\
\text { monosomy } 21 \text { and } X\end{array}$ \\
\hline 6 & FR & Segmental gain on $8 q, 9 q, 12 p$ and $13 q$ arms & Segmental loss on 9p arm & Monosomy 22 and $\mathrm{X}$ \\
\hline 7 & PL & Segmental gain on $2 p, 7 q, 8 q, 9 q, 12 p, 13 q$ arms & $\begin{array}{l}\text { Mosaic segmental loss on } 6 q, 7 p \text { and } \\
10 p \text { arms }\end{array}$ & \\
\hline 8 & MA & $\begin{array}{l}\text { Segmental gain on } 2 p, 8 q \text { and } 9 q \text { arms Mosaic segmental gain } \\
\text { on } 12 p \text { arm }\end{array}$ & Segmental loss on $9 p$ arm & Cryptic loss of tel $17 p$ \\
\hline 9 & MF & $\begin{array}{l}\text { Segmental gain on } 8 q \text { and } 9 q \text { arms Mosaic segmental gain } 12 p \\
\text { arm }\end{array}$ & Segmental loss on 9p arm & Cryptic loss of tel $17 p$ \\
\hline 10 & WDT & Segmental gain on $8 q, 9 q$ and $13 q$ arms & Segmental mosaic loss on $6 \mathrm{q}$ arm & Monosomy 22 \\
\hline
\end{tabular}
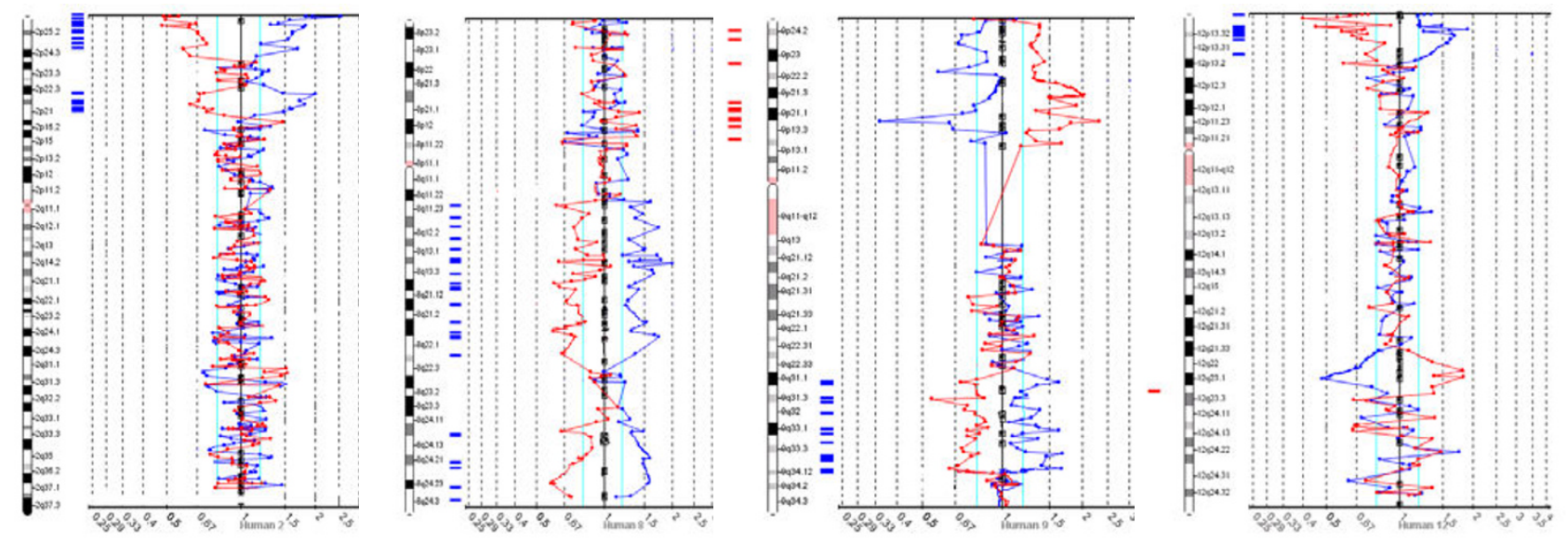

Gain on 2p24-2pTer and 2p21-2p22

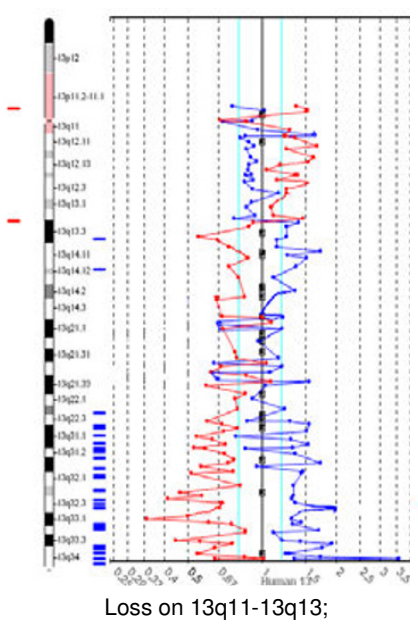

gain on $13 q 13-q 14$ and $13 q 22-13 q$ Ter

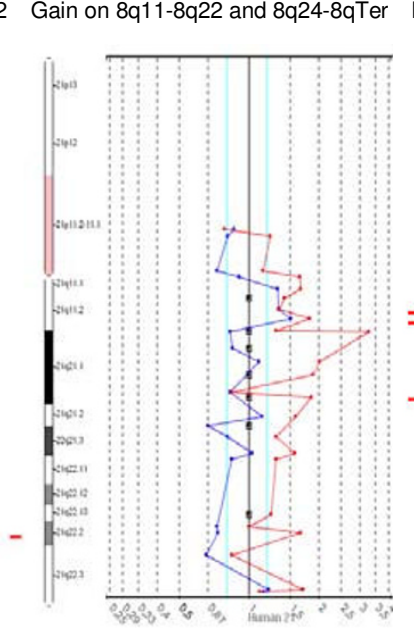

Loss of chromosome 21: Monosomy

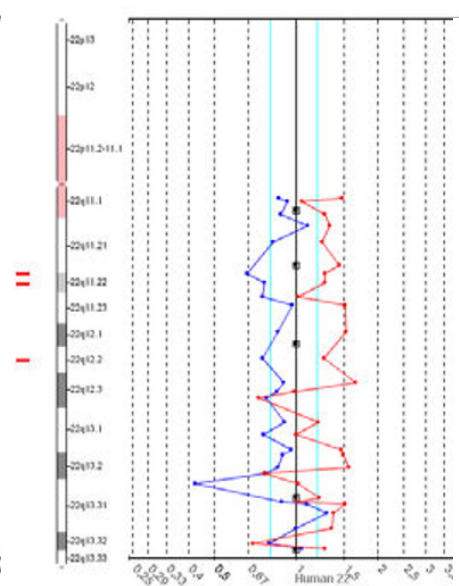

Loss of chromosome 22:Monosomy

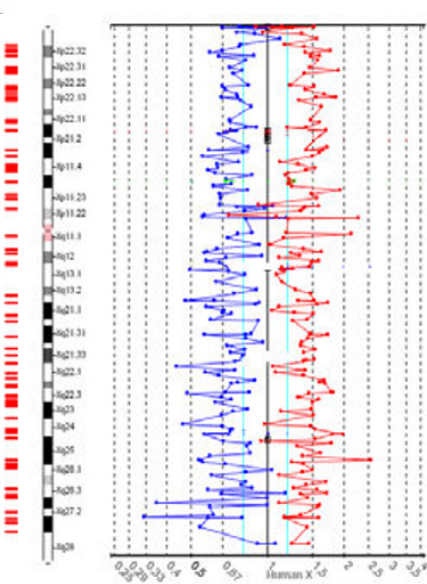

Loss of chromosome X: Monosomy

Figure I

examples of chromosomes profiles and abnormalities. 


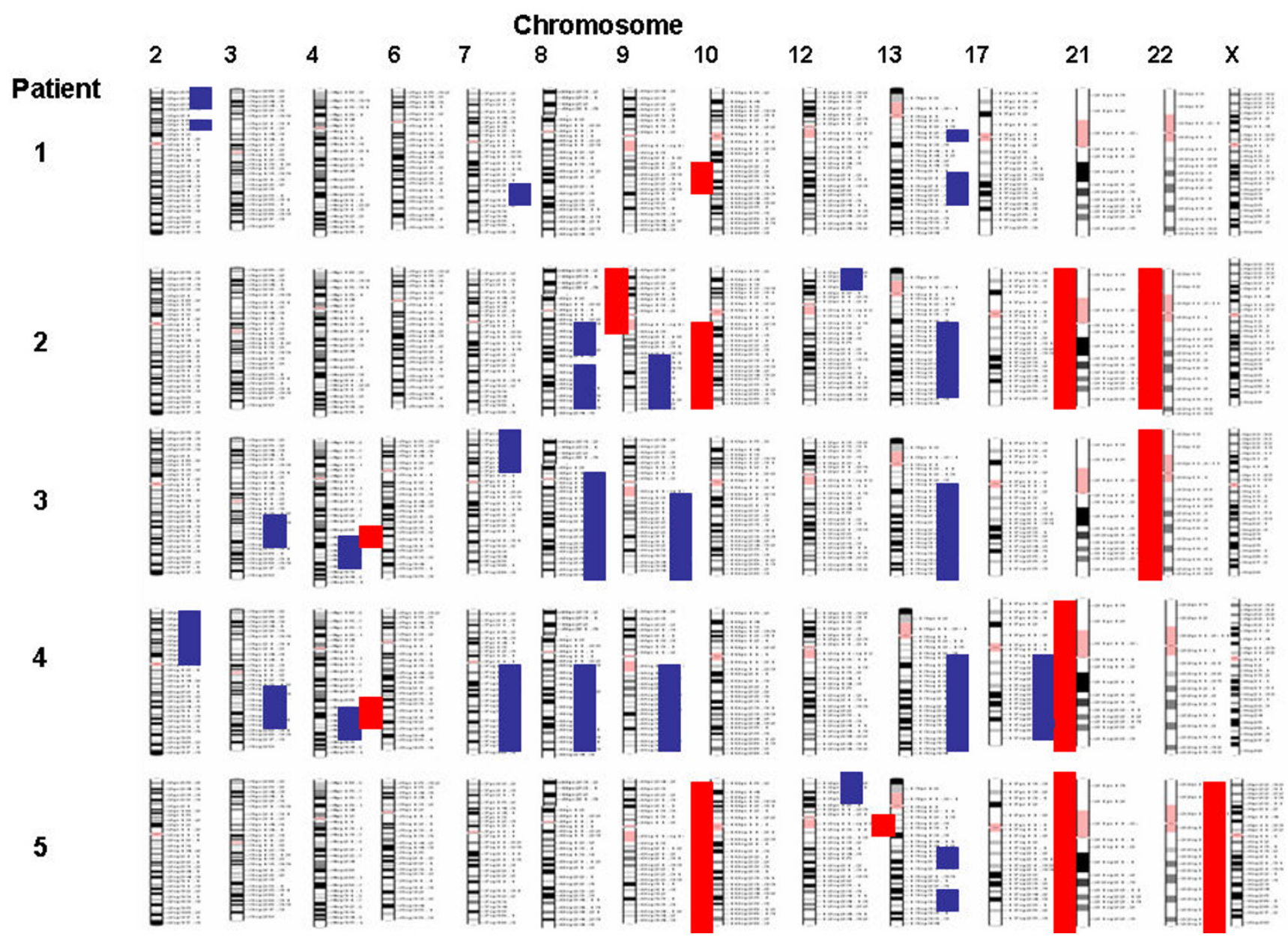

Figure 2

Genome profiling of patients I to 5 .

I [32]. Approaches to ovarian screening include transvaginal sonography, serum CA-125 markers or both, but these include limitations in sensitivity and specificity [33]. A rapid fall of CA 125 during chemotherapy predicts a favorable prognosis and could be used to redistribute patients on randomized clinical trials [34]. Gene expression and proteomic arrays were used to identify markers that can be used in combination with the clinical picture for early detection [35].

We observed both qualitative and quantitative differences as well as similarities between our data from array CGH on these ovarian tumors from familial cases and abnormalities noted by classical G-banding techniques or other molecular cytogenetic methods in the literature [36]. We noted for example 8 of the ten cases with gain of $8 \mathrm{q}$ and 9q.
G-band studies remain the gold standard in cytogenetics laboratories, but most such studies were carried on more advanced cancers and reveal significant abnormalities related to acquision of nuclear instability [37$39,29,40,41]$. Tharapel et al [42] reported a correlation between chromosome abnormalities and cancer stages such as presence of trisomy 7 and 10 in early stages of ovarian adenocarcinoma. In one of the largest studies, Tibiletti et al. [43] performed cytogenetic characterization of a cohort of 114 untreated ovarian epithelial tumors and concluded that there are three groups: "the first group included abnormalities common to all tumor classes (losses of chromosomes 6, 8, 10, 11, 15, 16, 17, 18, 19, 20, 21, 22, and X; gains of chromosomes 1, 3, 5, and 12 and 6q24-6qter deletions); the second group with specific abnormalities present in malignant but not in benign tumors (losses of chromosomes 2, 7, 13, and 14; gains of chromosome 4 and chromosome markers); and the last group included abnormalities unique to invasive carcino- 


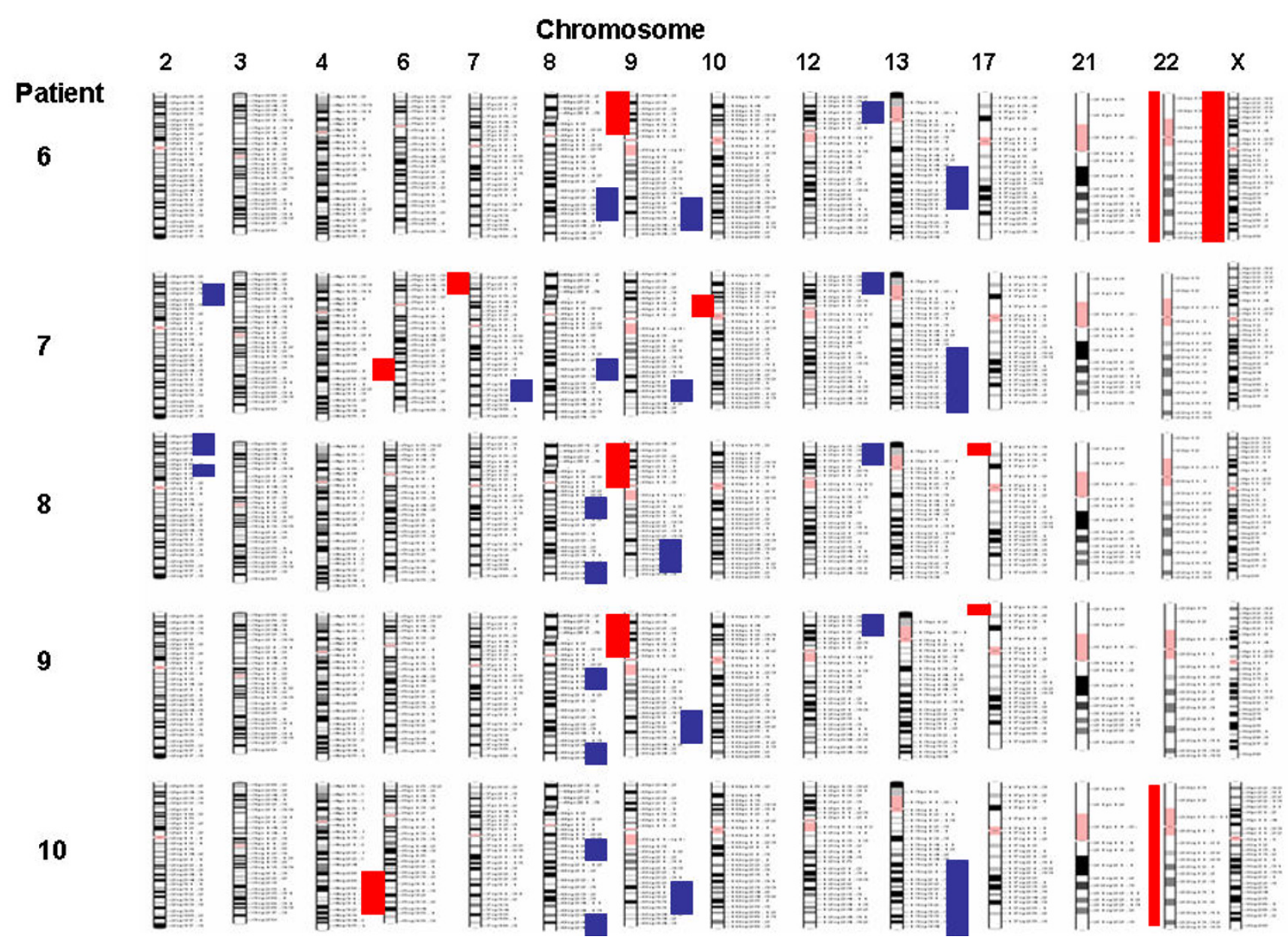

Figure 3

Genome profiling of patients 6 to 10 .

mas (loss of chromosome 4; gains of chromosomes 2, 7 , $8,9,10,16,17,18,19,20$, and $21 ; 6 q 16-6 q 24$ deletions: rearrangements of $3 p, 3 q, 13 q$, and $21 q$ regions). The analysis of 17 sporadic primary ovarian carcinomas by a combination of spectral karyotyping, CGH and expression microarrays and when the distribution of aberrations was normalized with respect to relative genomic length, chromosomes 3, 8, 11, 17 and 21 had the highest frequencies [44]. From in vitro murine model for ovarian cancer the application of microarrays CGH revealed genomic imbalances of chromosomes 4, 5, 7, 8, 9, 11, 15, 17 and X [45].

Aneuploidy assessment in interphase cytogenetics of chromosome 1, 11, 17 and $\mathrm{X}$ by fluorescence in situ hybridization (FISH) of 92 epithelial ovarian tumors identified numerical aberrations in $67 \%$ of mucinous carcinoma and $82 \%$ of invasive serous carcinomas but without significant relationship with either stromal invasion or tumor type except for monosomy $\mathrm{X}$ which was noted in invasive serous carcinoma [46]. An investigation of 7 stage III ovarian serous cancers by comparative genomic hybridization (CGH) revealed chromosomal aberrations in six patients with certain repeated changes including increased copy numbers of 1q, 2p, 2q, 3q, 6q, 8q, and $12 p$, and loss of $18 q$ and X [47]. CGH analysis of malignant peripheral primitive neuroectodermal ovarian tumors revealed different chromosomal abnormalities including loss of chromosomes $1 \mathrm{p}, 1 \mathrm{q}, 4 \mathrm{q}, 6 \mathrm{p}, 6 \mathrm{q}, 7 \mathrm{q}, 8 \mathrm{q}$, $13 \mathrm{q}$ and $19 \mathrm{q}$; as well as gain of $1 \mathrm{q}, 2 \mathrm{p}, 7 \mathrm{p}, 9 \mathrm{q}, 18 \mathrm{q}$ and $\mathrm{Xq}$ [48-50]. The use of CGH and tissue microarrays in ovarian carcinoma [51] showed a frequent chromosomal over presentation on $2 \mathrm{q}, 3 \mathrm{q}, 5 \mathrm{p}, 8 \mathrm{q}, 11 \mathrm{q}, 12 \mathrm{p}, 17 \mathrm{q}$ and chromosome 20 combined to an amplification of 59 different oncogenes loci.

Our data showed a loss of chromosome 10 or $10 \mathrm{q}$ material in three cases and $6 \mathrm{q}$ material in 4 cases. Loss of het- 


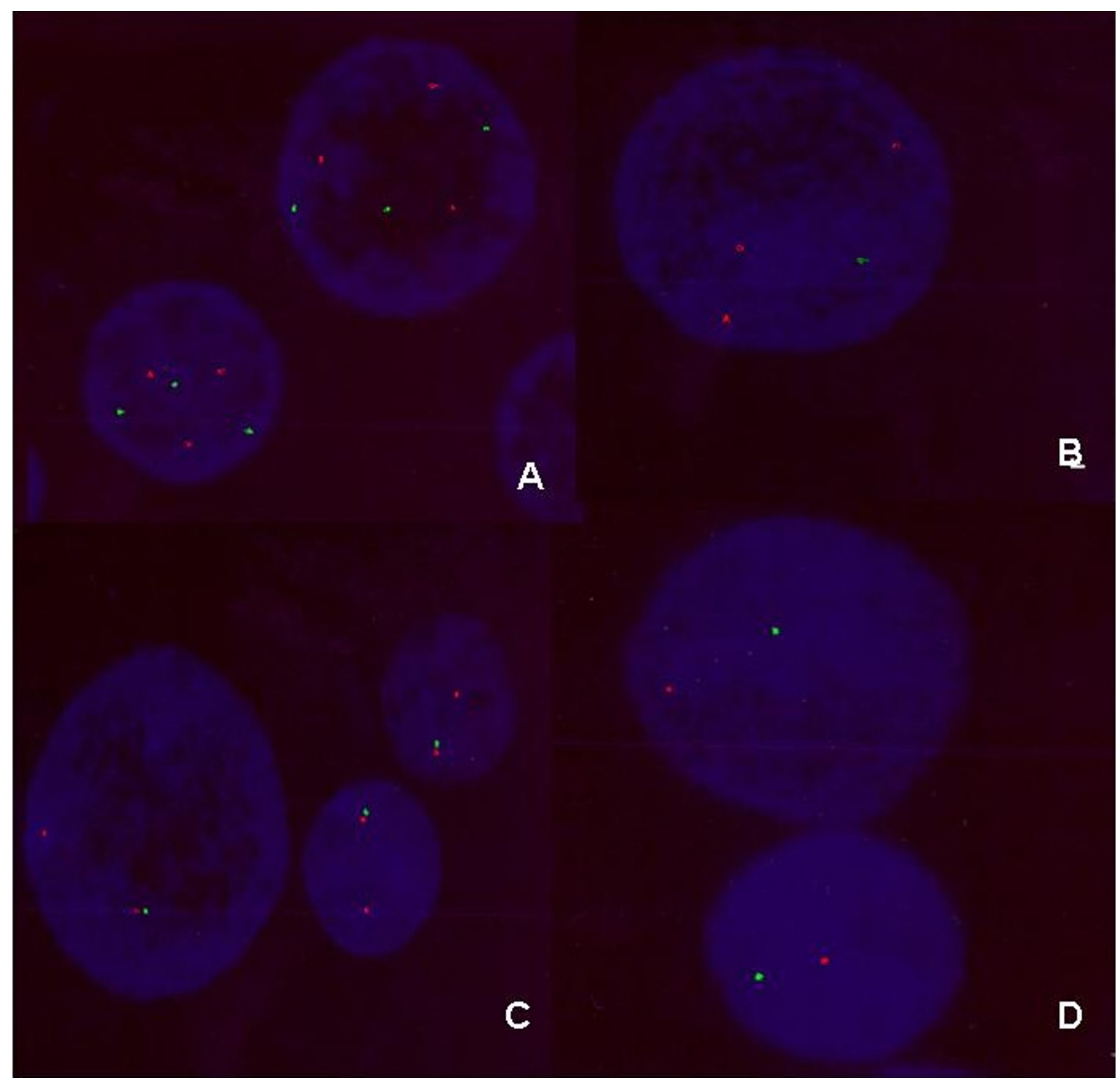

\section{Figure 4}

Examples of FISH data using BACs probes. A) Case 2: trisomy $8 q$ and I $3 q$ B) Case 5: trisomy $12 p$ and monosomy $X$. C) Case 6: disomy 9q monosomy 9p D) Case 10: monosomy 6q monosomy 22.

erozygosity (LOH) on 10q23 involving PTEN tumor suppressor gene is noted in about $30 \%$ of adenocarcinoma and was suggested as an important event in the progression of endometriosis to ovarian adenocarcinoma [52]. By FISH analysis Trisomies 1, 7 and monosomies 9 and 17 were observed in endometriosis, ovarian endometrioid adenocarcinoma and normal endometrium but the frequency of aneusomic cells was significantly higher in ovarian endometrioid carcinoma [10]. This may reflect an expansion of aberrant cells clones already present in endometriosis during the progression to cancer. Levan et al. [13] examined 98 endometrioid adenocarcinomas by CGH and reported 39 chromosomal regions displaying frequent DNA copy number alterations. The analysis of 81 ovarian cancers for LOH by Obata and Hoshiai [53] showed $60 \%$ with $\mathrm{LOH}$ on chromosome $6 \mathrm{q}$ and $40 \%$ on 
10q. Their data supported the hypothesis that endometrioid and ovarian carcinoma may arise though malignant transformation of endometriotic lesions.

Previous cytogenetics studies of adult germ cells tumors (GCTs) showed that $12 \mathrm{p}$ abnormalities are common phenomenon in more than $80 \%$ of GCTs. Our data showed 6 out 10 patients with segmental gain of 12 and mainly trisomy $12 \mathrm{p}$. The presence of three or mores copies of $12 \mathrm{p}$ may predict resistance to chemotherapy and treatment failure [54].

In our data we observed 3 cases with monosomy 21 and 4 cases with monotony 22 . The profiling of human chromosome 22 in ovarian carcinoma by Bentkiewicz et al [55] using high resolution gene copy and expression analysis detected 11 of 18 cases (60\%) with heterozygous deletions with various sizes in chromosome $22 \mathrm{q}$ and one case with total monosomy 22q. One of the major observations in this study is the presence of segmental gain of $8 \mathrm{q}$ and $9 q$ in eight of 10 cases. Several of these cases also had $9 p$ loss. To predict a potential markers of chemo resistant disease, the analysis of chromosomal changes in serous ovarian carcinoma by high resolution array CGH [14] revealed a frequent increase in DNA copy number on 1p36, 3q26, $8 \mathrm{q} 24,10 \mathrm{q} 26,12 \mathrm{p} 11,20 \mathrm{q} 13$ and 21q22 and frequent loss on 4p12, 5q13, 7q11, 8p23, 14q32, Xq13 and Xq21. From these data Kim et al [14] conclude that the most reliable combination of chromosomal aberrations for detecting chemo resistant disease was the loss on 13q32.1, 8p21.1. and 16p13 [56].

For genome profiling and high resolution molecular karyotyping, array comparative genome hybridisation (array CGH) methods appear to be far better as they do not suffer from dependence on having metaphase preparations and have much higher sensitivity and specificity for subtle genomic changes. Constitutional deletions as small as 40 $\mathrm{kb}$ have been detected using an array encompassing a 7 $\mathrm{Mb}$ interval of chromosome 22 with $90 \%$ coverage [57]. A-CGH can also provide a technically less demanding and more sensitive assay than classic $\mathrm{CGH}$ or even routine cytogenetics. A-CGH use is limited by the cost effective of this technology in routine cytogenetics laboratory and also by the ability to detect certain abnormalities such as tetraploidy and balanced translocations

\section{Conclusion}

It appears likely that in the next few years, array based CGH will become routinely used in clinical cytogenetics. The profiling studies of ovarian cancer by molecular karyotyping and Multiplex ligation-dependent probe amplification [58], expression micro arrays and MicroRNA signature [16,19] and proteome analysis will open the way to more exhaustive and systematic representation of the disease and will provide valuable information that may be helpful to elucidate the mechanism and the evolution of ovarian cancer [17].

\section{Materials and methods}

Tumor tissues were available from ten women with a familial history of ovarian carcinoma who underwent surgery for ovarian masses which required hysterectomy with bilateral ovariectomy at the University of Rome La Sapienza, Saint Andrea Hospital. The mean age of the ten patients studied was 60.5 yrs old.

We used human genomic micro arrays containing 2700 human/BAC/PAC clones (Human BAC Array-System, Perkin Elmer. USA). This array includes subtelomeric regions as well as critical areas spaced roughly $1 \mathrm{Mb}$ along each of the human autosomes as well as the $\mathrm{X}$ and $\mathrm{Y}$ chromosomes. For consistency and increased sensitivity and specificity, the arrayed clones were printed in duplicate. $2 \mu \mathrm{g}$ each of the test DNA extracted from the tumor samples and control DNA (female from Promega, Madison, WI) were digested with 80 units of EcoR 1 at $37^{\circ} \mathrm{C}$ overnight and then purified by Zemo Research's column (Orange, CA, USA). The test and reference DNAs were labeled with Cy3 and Cy5 using random prime labeling kit (Invitrogen, Carlsbad, California) to obtain a labeled probe size averaging 100 to $500 \mathrm{bp}$ in length. Cy5 labeled test DNA and Cy3 labeled reference DNA were co-precipated with $65 \mu \mathrm{g}$ of Cot- 1 DNA and $35 \mu \mathrm{g}$ of Salmon sperm DNA. Forward and reverse hybridization switching of dyes was performed to address issues related to dye specificity and strength. Then the probes were dissolved in $10 \mu \mathrm{l}$ of distilled water and mixed with $50 \mu$ l of hybridization solution (50\% formamide, $10 \%$ dextran sulphate in $2 \times$ SSC). The hybridization mix then was denatured at $73^{\circ} \mathrm{C}$ for 12 min and followed by $40 \mathrm{~min}$ al $37^{\circ}$ for annealing. For hybridization and washing we used an automated system (Tray Mix) based on chaotic hybridization approach and developed by BIOTRAY sarl (69007 Lyon France).

Hybridized and washed array slides were analyzed with InnoScan 700A scanner (INNOPSYS, 313901 Carbonne, France). The software recognizes the regions of fluorescent signal, determines signal intensity and compiles the data into a spreadsheet that links the fluorescent signal of every clone on the array to the clone name, its duplicate position on the array and its position in the genome. The software was also used to normalize the Cy5:Cy3 intensity ratios for each data point. Normalization was such that the summed Cy5 signal equals the summed Cy3 signal. The normalized Cy3:Cy5 intensity ratios were computed for each two slides and plotted together for each chromosome. The linear order of the clones in reconstituted in the ratio plots consistent with an ideogram, such that the $\mathrm{p}$ 
terminus in to the left and the q terminus in to the right of the plot.

For data analysis we assign a ratio plot such that gains in DNA copy number at particular locus are observed as the simultaneous deviation of the ratio plots from a modal value of 1.0, with the blue ratio plot showing a positive deviation (upward) while the red ratio plot shows a negative deviation at the same locus (downward). DNA copy number losses show the opposite pattern. In selected cases, fluorescent in situ hybridization (FISH) was used to confirm the A-GCH findings.

\section{Competing interests}

The authors declare that they have no competing interests.

\section{Authors' contributions}

All authors read and approved the final manuscript

\section{Acknowledgements}

We would like to thank Ons Shili for the technical support and the data analysis. This project was founded by rome university la Sapienza. Italy

\section{References}

I. Caserta D, Marci R, Porzio G, Di Roma E, Moscarini M: Pelvic relapses in ovarian cancer: role ofCA I 25, transvaginal ultrasound and Color Doppler. Europ J Gynecol Oncol 2003, 24(34):269-70.

2. Myers E, Havrilesky I, Kulasingam S, Sanders G, Cline K, Gray R, Berchuk A, McCrory D: Genomic tests for ovarian cancer detection and management. Evid Rep Technol Assess 2006, I 45: I- I00.

3. Rustin G, Timmers P, Nelstrop A, Shreeves G, Bentzen S, Baron B, Piccart M, Bertelsen K, Stuart G, Cassidy J, Eisenhauer E: Comparison of CA-I 25 and standart definitions of progression of ovarian cancer in the intergroup trial of cisplatin and paclitaxel versus cisplatin and cyclophosphamide. J Clin Oncol 2006, 24(I):45-5I.

4. Gebhart E, Liehr T: Patterns of genomic imbalances in human solid tumors (review). Int J Oncol 2000, I 6(2):383-399.

5. Weise A, Liehr T, Efferth T, Kuechler A, Gebhart E: Comparative M-FISH and CGH analyses in sensitive and drug-resistant human T-cell acuate leukemia cell lines. Cytogenet Genome Res 2002, 98(2-3): II8-125.

6. Prasad M, Bernardini M, Tsalenko A, Marrano P, Paderova J, Lee CH, Ben-Dor A, Barret M, Squire J: High definition cytogenetics and oligonucleotide aCGH analyses of cisplatin-resistant ovarian cancer cells. Genes Chromosomes Cancer 2008, 57(5):427-436.

7. Bast RC: Early detection of ovarian cancer: new technologies in pursuit of a disease that is neither common nor rare. Trans Am Clin Climatol Assoc 2004, I I 5:233-48.

8. Simon R, Desper R, Papadimitriou CH, Peng A, Alberts DS, Taetle R, Trent JM, Schäffer AA: Chromosome abnormalities in ovarian adenocarcinoma: III. Using breakpoint data to infer and test mathematical models for oncogenesis. Genes Chromosomes Cancer 2000, 28(I): 106-20.

9. Liehr T, Stübinger A, Thoma K, Tulusan HA, Gebhart E: Comparative interphase cytogenetics using FISH on human ovarian carcinomas. Anticancer Res 1994, I4(I A): I83-188.

10. Korner M, Burkhardt E, Mazzuchelli L: Higher frequency of chromosomal aberrations in ovarian endometriosis compared to extragonadal endometriosis: A possible link to endometriod adenocarcinoma. Mod Pathol 2006, I 9(I 2): I615-1623.

II. Mhawech P, Kinkel K, Vlastos G, Pelte MF: Ovarian carcinomas in endometriosis: an immunohistochemical and comparative genomic hybridization study. Int J Gynecol Pathol 2002, 2 I (4):40 I-406.

12. Dent J, Hall GD, Wilkinson N, Perren TJ, Richmond I, Markham AF, Murphy $\mathrm{H}$, Ben SM: Cytogenetic alterations in ovarian clear cell carcinoma detected by comparative genomic hybridisation. Br J Cancer 88: 1578-1583. 2003 May 19

13. Levan K, Partheen K, Ostergerg L, Helou K, Horvath G: Chromosomal alteration in $\mathbf{9 8}$ endometrioid adenocarcinomas analysed with comparative genomic hybridization. Cytogenet Genome Res 2006, II 5(I): 16-22.

14. Kim S, Kim J, Kim Y, Kim J, Kim S, Yoon B, Nam I, Kim H: Analysis of chromosomal changes in serous ovarian carcinoma using high resolution array comparative genome hybridization: Potential presdictive markers of chemoresistant disease. Genes Chromosomes Cancer 2007, 46(I): I-9.

15. Choi Y, Kim J, Kwon M, Choi J, Kim T, Bae D, Koh S, In Y, Park Y, $\mathrm{Kim} S$, Ahn G, Shin Y: Expression of tight junction protein claudin 3 and claudin 4 in ovarian serous adenocarcinoma with prognostic correlation. Histol Histopathol 2007, 22(II): I I85-II 195.

16. Fehrmann R, Li X, Vander Zee A, De Jong S, Meerman G, De Vries E, Crijns A: Profiling studies in ovarian cancer: $A$ review. The Oncologist 2007, 12(8):960-966.

17. Gagné J, Ethier C, Gagné P, Mercier G, Bonicalzi M, Mes-Masson A, Droit A, Winstall E, Isabelle $M$, Poirrier G: Comparative proteome analysis of human epithelial ovarian cancer. Proteome Sci 2007, 24:5-16.

18. Grisaru D, Hauspy G, Prasad M, Albert M, Murphy K, Covens A, Macgregor P, Rosen B: Microarray expression idebtification of differentially expressed genes in serous epithelial ovarian cancer compared with bulk normal ovarian tissue and ovarian surface scrapping. Oncol Rep 2007, 18(6): | $347-1356$.

19. lorio M, Visone R, DI Leva G, Donati V, Petrocca F, Casalini P, Taciolli C, Volinia S, Liu C, Alder H, Callin G, Menard S, Croce C: MicroRNA signature in human ovarian cancer. Cancer Res 2007, 67(18):8699-707.

20. Gorringe K, Jacobs S, Thompson E, Sridhar A, Qiu W, Choong D, Campbell I: High resolution single nucleotide polymorphism array analysis in epithelial ovarian cancer reveals numerous microdeletions and amplifications. Clin Cancer Res 2007, 13(16):4731-4739.

21. Nakayama K, Nakayama N, Jinawath N, Salani R, Kurman R, Shih I, Wang T: Amplicon profile in ovarian serous carcinoma. Int J Cancer 2007, I 20(I2):2613-26I7.

22. Benkhalifa M, Kasakyan S, Clement P, Baldi M, Tachdjian G, Demirol A, Gurgan T, Fiorentino F, Mohammed M, Qumsiyeh M: Array comparative genome hybridization profiling of first trimester spontaneous abortion that failed to grow in vitro. Prenat Diag 2005, 25( 10$): 894-900$.

23. Carvalho B, Ouwerkek E, Meijer G, Ylstra B: High resolution microarray comparative genomic hybridisation analysis using spotted oligonucleotides. J Clin Pathol 2004, 57(6):644-646.

24. Oostlander A, Meijer G, Ylstra B: Microarray-based comparative genomic hybridization and it's application in human genetics. Clin Genet 2004, 66(6):488-495.

25. Rickman L, Fiegler H, Carter N, Bobrow M: Prenatal diagnosis by array-CGH. Eur J Med Genet 2005, 48(3):232-240.

26. Shaw-Smith C, Redon R, Richman L, Rio M, Willatt L, Fiegler $H$, Firth H, Sanlaville D, Winter R, Colleux L, Bobrow M, Cartner N: Microarray based comparative genomic hybridization (arrayCGH) detect submicroscopic chromosomal deletions and duplication in patients with learning disability/mental retardation and dysmorphic futures. J Med Genet 2004, 4I(4):24I-248.

27. Shaffer L, Bejjani B: A cytogenetic perspective on genomic microarray. Hum reprod Update 2004, I0(3):22I-226.

28. Ylstra B, ljsse IP Van den, Carvalho B, Brakenhoff R, Meijer G: BAC to the future or oligonucleotides: a perspective for micro array comparative genomic hybridization (array CGH). Nucleic Acids Res 2006, 34(2):445-450.

29. Mayr D, Kaltz-Wittmer C, Arbogast S, Amann G, Aust D, Diebold J: Characteristic pattern of gentic aberration in ovarian granulosa cell tumours. Mol Pathol 2002, I 5(9):95I-957.

30. Knijnenburg J, burg $M$ Van der, Nilsson P, Ploos $H$ van Amstel, Tanke $\mathrm{H}$, Szuhai K: Rapid detection of genomic imbalances using micro-arrays consisting of pooled BACs covering all human chromosomes arms. Nucleics Acid Re 2005, 12(33): 159. 
31. Shaffer L, Bejiani B: Medical application of array CGHand the transformation ofclinical cytogenetics. Cytogenet Genome Res 2006, II 5(3-4):303-309.

32. Bast RC: Status of tumor markers in ovarian cancer screening. J Clin Oncol 2003, 21 ( 10 suppl):200-205.

33. Caserta D, Marci R, Tatone c, Dolo V, Di Roma E, Fazi A, Moscarini M: Serum CA I 25 level modifications in women undergoing repeated IVF cycles. Eur J Gynecol Oncol 2006, 27(4):353-5.

34. Bast RC, Bagdwell D, Lu Z, Marquez R, Rosey D, Liu I, Baggherly KA, Atkinson E, Skates S, Zhang Z, Lokshin A, menon D, Jacobs I, Lu K: New tumor markers: CA 125 and beyond. Int J Gynecol Cancer 2005, I 5(Suppl 3):274-8I.

35. Bast RC Jr: Early detection of ovarian cancer: new technologies in pursuit of a disease that is neither common nor rare. Trans Am Clin Climatol Assoc 2004, I I 5:233-248.

36. Wolf N, AbdulKarim F, Farver C, Schrock E, du Manoir S, Schwartz $S$ : Analysis of ovarian borderline tumors using comparative genomic hybridization and fluorescent in situ hybridization. Genes Chromosomes Cancer 1999:307-315.

37. Sahin I, Yilmaz Z, Sahin F: Cytogenetic analysis in serous papillary adenocarcinoma of the ovary. Eur J Gynaecol Oncol 2004, 25(5):585-586.

38. Huang N, Gupta m, Varghes S, Rao S, Luke S: Detection of numerical chromosomal abnormalities in epithelial ovarian neoplasms by fluorescents in situ hybridization (FISH) and a review of the current literature. Appl Immunohistochem Mol Morphol 2002, I0(2): 187-193.

39. Hauptmann S, Denkert C, Koch I, Petersen S, Schluns K, Reles A, Dietel M, Petersen I: Genetic alteration in epithelial ovarian tumours analysed by comparative genomic hybridization. Hum pathol 2002, 33(6):632-64I.

40. Helou K, Padilla-Nash H, Wangsa D, Karlsson E, Ostergerg L, Karlsoon $\mathrm{P}$, Ried $\mathrm{T}$, Knutsen $\mathrm{T}$ : Comparative genome hybridization reveals specific genomic imbalances during the genesis from benign throught borderline to malignant ovarian tumours. Cancer Genet Cytogenet 2006, I 70(I): I-8.

4I. Streblow R, Dafferner A, Nelson M, Fietcher M, West W, Stevens R, Gatalica Z, Novak D, Bridge J: Imbalance of chromosomes 4, 9, and $\mathbf{I} 2$ are recurrent in the thecoma-fibroma group of ovarian stromal tumors. Cancer Genet Cytogenet 2007, 178(2): $135-140$

42. Tharapel SA, Qumsiyeh MB, Photopulos G: Numerical chromosome abnormalities associated with early clinical stages of gynecologic tumors. Cancer Genet Cytogenet I99I, 55(I):89-96.

43. Tibiletti M, Bernasconi B, Taborelli M, Facco c, Riva C, Capelle C, Franchi M, Binelli G, Acquatti F, Taramelli R: Genetic and cytogenetic observations among different types of ovarian tumours are compatible with progression model underlying ovarian tumourigenesis. Cancer Genet Cytogenet 2003, I 46(2): I 45- I 53.

44. Bayani J, Brenton J, Macgregor P, Beheshti B, Albert M, Nallainathan D, Karaskova J, Rosen B, Murphy J, Laframboise S, Zanke B, Squire J: Parallel analysis of sporadic primary ovarian carcinomas by spectral karyotyping, comparative genomic hybridization and expression microarrays. Cancer Res 2002, 62(I2):3466-3476.

45. Urzua U, Frankenberger C, Gangi L, Mayer S, Burkett S, Munroe D: Microarray comparative genomic hybridization profile of murine model for epithelial ovarian cancer reveals genomic imbalances resembling human ovarian carcinomas. Tumour Biol 2005, 26(5):236-244.

46. Evans M, McDicken I, Herrington C: Numerical abnormalities of chromosomes I, II, 17 and $X$ are associated with stromal invasion in serous and mucinous epithelial ovarian tumours. J Pathol 1999, I 89:53-59.

47. Fishman A, Shalom-Paz E, Fejgin M, Gaber E, Altaras M, Arniel A: Comparing the genetic changes detected in the primary and secondry tumour sites of ovarian cancer using comparative genome hybridization. Intl $\mathrm{Jl}$ of Gynecol Cancer 2005, 15(2):261-266.

48. Wang N: Cytogenetics and molecular genetics of ovarian cancer. Am J Med Genet 2002, I I5(3): I57-I63.

49. Chow S, Lin M, Shen J, Wang S, Jong Y, Chien C: Analysis of chromosome abnormalities by comparative genomic hybridization in malignant peripheral primitive neuroectodermal tumour of the ovary. Gynecol Oncol 2004, 92(3):752-760.
50. Lin $\mathrm{Y}$, Eng H, Jan $\mathrm{Y}$, Lee H, Ho W, Liou C, Lee W, Tzeng C: Molecular cytogenetics of ovarian granulosa celltumours by comparative genomic hybridization. Gynecol Oncol 2005, 97(I):68-73.

5I. Schraml P, Schwerdtfeger G, Burkhalter F, Raggi A, Ashmidt D, Fuffalo T, King W, Wilber K, Mihatsch M, Moch H: Combined array comparative genomic hybridization and tissue microarray analysis suggest PAKI at I IqI3.5-q I 4 as critical oncogene target in ovarian carcinoma. Am J Pathol 2003, 163(3):985-992.

52. Ali-Fehmi R, Khalifeh I, Bandyopadh S, Laurence W, Silva E, Lia D, Sarkar F, Munkarah A: Patterns of loss of heterozygosity at $10 \mathrm{q} 23.3$ and microsattelite instability in endometriosis, atypical endometriosis, and ovarian carcinoma arising in association with endometriosis. Int J Gynecol Pathol 2006, 25(3):223-229.

53. Obata $\mathrm{K}$, Hoshiai $\mathrm{H}$ : Common genetic change between endometriosis and ovarian cancer. Gynecol Obstet Invest 2000, 50(Suppl I):39-43.

54. Ilson D, Bosi G, Motzer R, Dmitrovsky E, Chaganti R: Genetic analysis of germ cell tumour: current progress and future prospective. Hematol Oncol Clin North Am I991, 5(6): I 27|-83.

55. Benetkiewcz M, Wang Y, Shaner M, Wang P, Mantripragada K, Buckley $P$, Kristensen G, Borresen-Dale A, Dumanski JP: Hight-resolution gene copy number and expression profiling ofhuman chromosome 22 in ovarian carcinomas. Genes Chromosomes Cancer 2005, 42(3):228-237.

56. Buys T, Chari R, Lee E, Zhang M, MacAulay C, Lam S, Lam W, Ling V: Genetic changes in the evolution of multidrug resistance for cultured human ovarian cancer. Genes Chromosomes Cancer 2007, 46( I 2): 1069-1079.

57. Bruder C, Hivela C, Papia Paez I, Fransson I, Segraves r, Hamilton G, Zhang X, Evans D, Wallace A, Baser M, Zucman-Rossi J, Hergersberg M, Boltshauser E, Papi L, Rouleau G, Poptodorov G, Jordanova A, Rask-Andersen H, Kluwe L, Mautner V, Sainio M, Hung G, Mathiesen T, Moller C, Pulst S, Harder H, Heiberg A, Honda M, Nimura M, Sahlen S, Blennow E, Albertson D, Pinkel D, Dumanski J: Hum Mol Genet 200I, I0(3):27I-282.

58. Nowee M, Snijders A, Rockx D, De Wit R, Kosma V, Hamalainen K, Shouten J, Verheigen R, Van Diest P, Albertson D, Dorsman J: DNA profilingof primary serous ovarian and fallopian tube carcinomas with array comparative genome hybridization and multiplex ligation-dependent probe amplification. I Pathol 2007, 2 I 3(I):46-55.

Publish with Bio Med Central and every scientist can read your work free of charge

"BioMed Central will be the most significant development for disseminating the results of biomedical research in our lifetime. "

Sir Paul Nurse, Cancer Research UK

Your research papers will be:

- available free of charge to the entire biomedical community

- peer reviewed and published immediately upon acceptance

- cited in PubMed and archived on PubMed Central

- yours - you keep the copyright 